The medulla showed attached to it at the cerebellar-pontine angles, two small white nodules, attached to the pia mater by broad pedicles, one to one and a half $\mathrm{cm}$. in diameter, greyish-white in color, and offering little resistance to the knife (Fig. 1). These nodules showed on microscopical examination an appearance similar to that of the tumor in the spinal canal.

Microscopically. in stained sections, the tumors over the medulla show masses of large spherical fat cells, divided into lobes by strands of connective tissue, which spring apparently from a greatly thickened pia mater. The fat of these cells stains like normal fat with Sharlach $R$ and Osmic acid. The tumors contain several large vessels, and are on the whole distinctly vascular. They are partially encapsulated by a thin band of connective tissue, probably the remains of the arachnoid. The spinal cord appears throughout greatly flattened and distorted, and connected closely throughout its length with a fatty tumor, of the same nature with those in the medulla, in which are imprisoned several nerve roots. (Figs. 3 and 5.) The connective tissue capsule is thicker than that seen in the tumor over the medulla. 'The filum terminale is encased in a similar fatty growth, which lies between a greatly thickened pia and a fibrous tissue capsule representing the arachnoid. The cauda equina appears as several nerve trunks encased in a fibrous tissue capsule and separated by diffuse masses of fatty tissue resembling that seen in the medulla and the cord, the whole being surrounded by a thick connective tissue capsule. In the conus medullaris there are several small ependyma-lined cysts with neuroglia tissue in the intervening spaces (Fig. 5). Throughout the tumor, there is no sign of embryonic fatty tissue or of anything which would indicate rapid growth. In the cervical region, however, the remains of the dorsal columns are represented by scattered nervebundles separated by strands of fibrous tissue continuous with that of the pia mater, in which are numerous fat cells, an appearance which suggests that there was at one time some degree of active invasion of the cord itself by the lipomatous cells. This tumor, therefore, must be regarded as benign and of congenital origin.

Microscopically then, we find that the tumor is intradural, lipomatous in nature, and essentially benign, though showing some evidence of slight invasion of the substance of the cord itself. The growth is surrounded by the pia arachnoid.

Finally, from perusal of the literature, it is evident that such a condition is exceedingly rare, except in connection with spina bifida. Furthermore, in the few cases where it has occurred in the absence of the latter condition, there has always been, with one exception, either some associated congenital malformation or something in the structure of the tumor itself to suggest a congenital origin. In brief, the question arises whether such a condition can arise independently of other congenital defects. The extensive and symmetrical involvement of the spinal cord makes this case unique.

Let us summarize briefly the findings in this case. Anatomically there are present two small white tumors at the cerebellar-pontine angles, and a spinal cord symmetrically en- larged throughout its length, except for a constriction a few $\mathrm{cm}$. above the terminal filament, the enlargement being due to a similar firm white growth inside the spinal membranes, which has flattened the cord itself and crowded it ventrally. Microscopic examination shows this growth to be composed of cells having the appearance of normal fat cells, the fat contents of which react to Sharlach $R$ and Osmic acid, like normal human fat. The fatty growth is entirely limited to the confines of the pia arachnoid. In addition there are present cleft-palate and hare-lip, absence of the left kidney and ureter, and chronic internal and external hydrocephalus. REFERExces.
1 Von Recklinghausen: Untersuchungen über Spina Bifida. Vir-
chow's Archiv., 105. 1886.
2 Gowers: Trans. Path. Soc., London, Vol, 27.
8 Braubach: Archiv, für Psychiatrie, Vol. 15, 1884, p. 489.
For a brief general treatment of the subject the reader is re-
ferred to Lubarsch-Ostertag, "Frgebnisse der Pathologie und Anatomie," 1903; Erste Abteilung, p. 468.

DESCRIPTION OF FIGURES.

Fig. 1. Cerebellum, inverted, showing fatty tumors at cerebellar pontine angles.

FIa. 2. Spinal cord with the dura reflected, showing the cord and growth enveloped in the pia-arachnoid.

FIG. 3. Section of cervical cord, osmic acid impregnation, picric acid and acid fuchsin counterstain. Note flattened cord and connective tissue on dorsal surface, which surrounds nerve bundles in the dorsal columns.

Fia. 4. Section of lower lumbar cord; same technic as Fig. 3. FIG. 5. Longitudinal section through the conus medullaris, showing fatty tumor and ependyma. lined canals.

\section{THE ABUSE OF THE X-RAYS IN THE TREATMENT OF SKIN AFFECTIONS.}

BY JOHN T. BOWEN, M.D., BOSTON.

THE attitude of the practitioner of medicine toward the adoption of new therapeutic measures must be regarded as essentially dependent on individual temperament. A short and easy road to a permanent cure is the aim of everyone engaged in trying to heal the sick, and to those having special opportunities, the testing of new remedies and methods of treatment is a privilege of the utmost importance and value. Such a privilege, however, is not vouchsafed to the many, and for them the decision as to what remedies are safe or valuable for present use, must be based on the testimony of others. It is here that the matter of temperament thrusts itself into the foreground. By one of somewhat conservative nature, who has seen many methods that have been heralded as marvellous in their results, either wholly superseded or reduced to a very subordinate place in the catalogue of resources, much is demanded of a new method before its adoption,--above all, a reasonable certainty that it will at least do no harm. For the enthusiast anything new is attractive, and the calm deliberation as to whether a worse subsequent condition may result, is consistently lacking.

The discovery of the Roentgen rays offered at the outset hopes of a wide field of application in the treatment of skin diseases. These hopes have been on the whole only partially realized. 


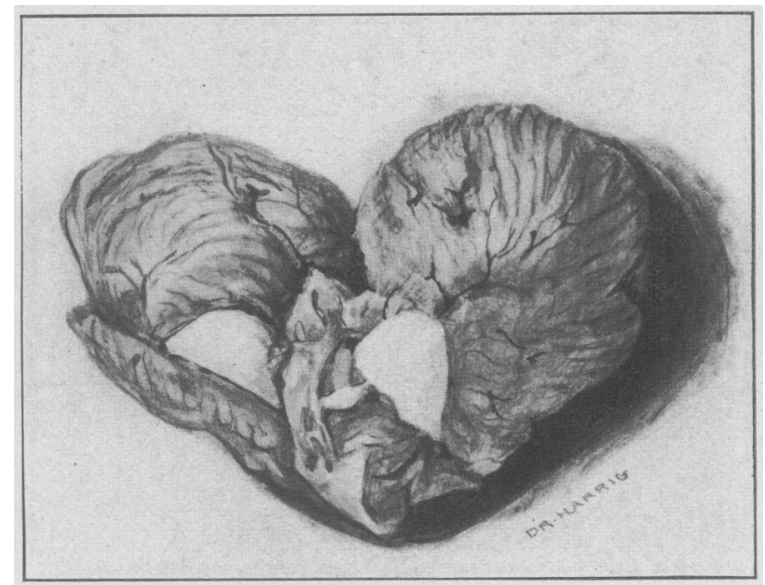

Fig. 1.

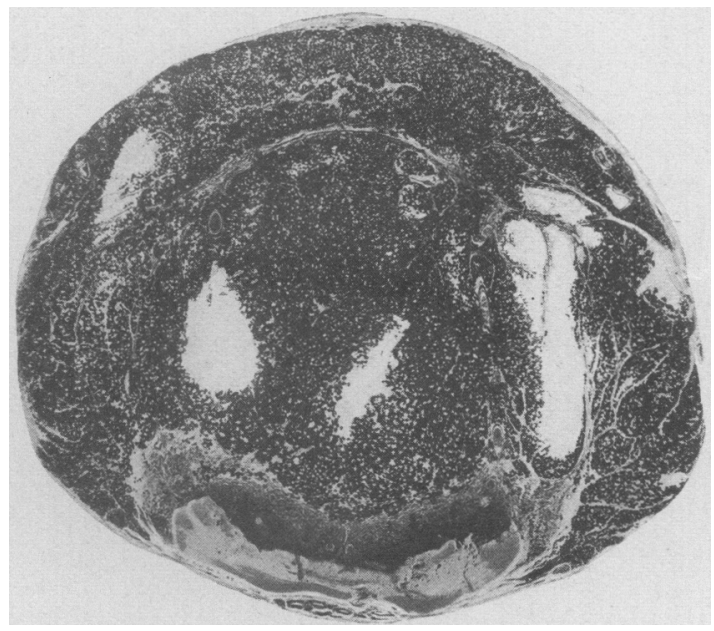

Fli. 3.

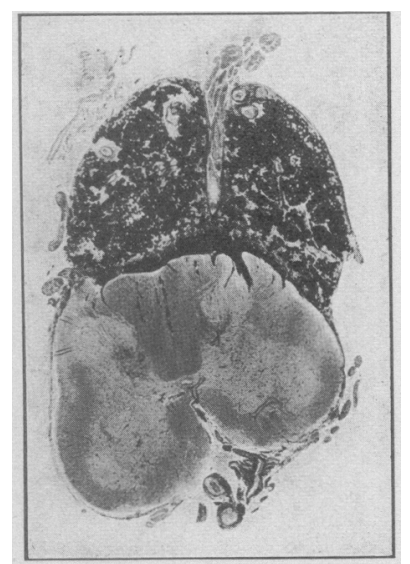

FIG. 4.

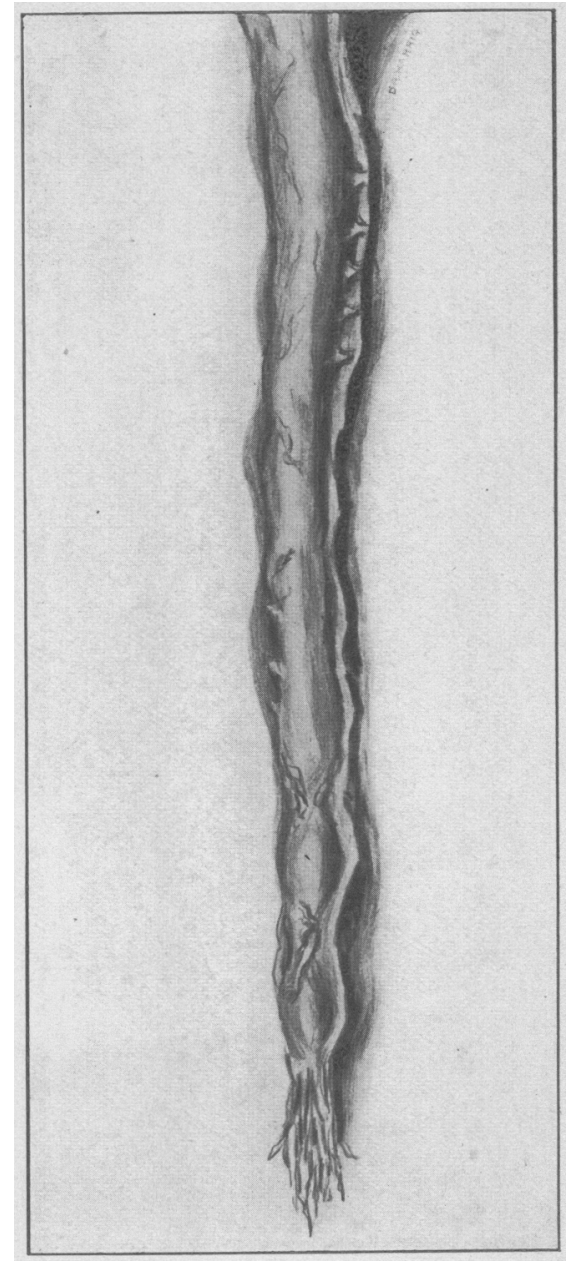

Fıg. 2.

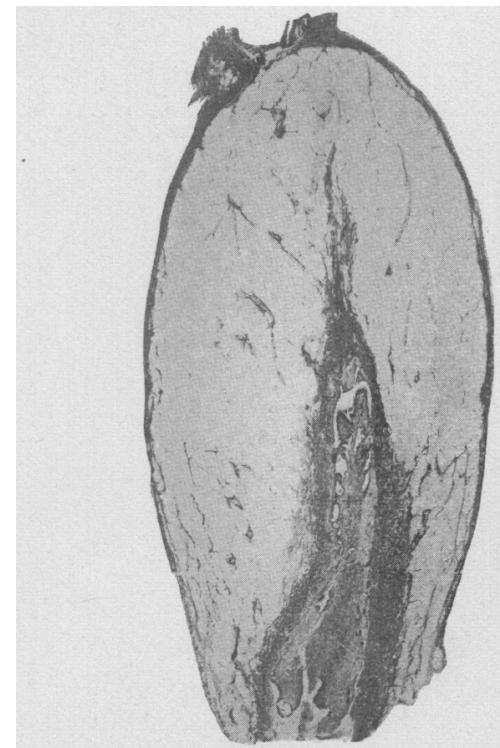

FIG. 5.

The Boston Medical and Surgical Journal as published by 
The place of the x-rays in dermatological therapeuties is at present a limited one, not so extended as that of many of the older methods that at times have seemed in danger of eclipse. This place, although small, should, however, be reserved for it. Unfortunately, the abuses of this treatment have had the result in great measure of prejudicing against its beneficial uses. Briefly, the legitimate use of the $x$-ray in this class of diseases is confined chiefly to the following cases: (1) Surgically inoperable epitheliomata, especially those involving the orbit of the eye. (2) Epitheliomata, or other malignant neoplasms in cases in which the patient absolutely refuses radical surgical intereference. (3) Small cutaneous epitheliomata in certain selected cases, in which a good cosmetic result is very important. (4) Sycosis, and obstinate pruritus of local or general character. (5) In a few other dermatoses, such as obstinate patches of psoriasis and eczema, in mycosis fungoides, and in a few rare affections, the x-ray may occasionally be used with great advantage.

The disadvantages of the x-rays are chiefly those resulting from its improper use. The question of susceptibility has been much discussed, and need not concern us now. My chief object is to call attention to the disfiguring results produced by many who make use of this method without proper training or experience. To use this method properly and safely one should have had a certain apprenticeship. No one, however brilliant, can seize a knife for the first time and perform expert surgery. In the same way, no practitioner can buy an x-ray outfit and properly treat, without practice, skin affections of which he has little knowledge. He thinks, perhaps, that he is sure of his diagnosis, and has read statements that the $\mathrm{x}$-ray has given wonderful results in similar cases. It is from such sources as this that the many disfiguring scars and blemishes are produced, that have the double misfortune of prejudicing other physicians or patients against the legitimate use of this method. Such instances have come to my knowledge with deplorable frequency of late. To cite one or two recent cases at random:-

CASE 1. A woman of 33 had had an erythematous and scaling eczema of the neck and parotid region and arms that had extended over several years and had not yielded to treatment. For nine months she had had a weekly treatment by the application of the $x$-rays to the affected parts. When seen, the whole of the area that had been exposed to the treatment was covered with pronounced telangiectases and atrophic scars. On the arms there had developed in addition a sclerodermatous condition. The eczematous condition was still present but was masked by the disfigurement resulting from the treatment.

CASE 2. A woman of 45 had been exposed several times to the $x$-rays by a dentist on account of an obscure pain in the jaw. When seen there was marked pigmentation, erythema and scaling of the whole of the left cheek, to which the rays had been applied. The hair had fallen completely over the temporal region, which had not been properly protected from the action of the rays.

CASE 3. A woman of 30 had had four years' previous to the time when she came for relief, a number of exposures to the $x$-ray for the removal of what she describes as a fine lanugo growth of hair on the chin and lower parts of the cheeks. The whole surface thus exposed was covered with numerous disfiguring telangiectases, and superficial and atrophic scars, so that the patient was much embarrassed when appearing in society. I have seen and treated this patient for the disfigurement described quite constantly for the last three years, and she is still under my care and following my instructions. I have succeeded in accomplishing a good deal as far as lightening the effect produced by the telangiectases is concerned. A partial improvement is, however, all that can be hoped for in such a case, but the disfigurement was so marked that the prospect of any betterment was eagerly welcomed.

These instances could be largely multiplied from my own experience alone. Conversation with those who have personal acquaintance with x-ray exposures confirms these observations.

Dr. Walter J. Dodd writes to me as follows: "With regard to our conversation of some days ago, concerning the injuries resulting from the use of the x-ray in both therapeutic and radiographic work, I would say that I have seen several cases this year that have shown marked erythema, and one case a severe alopecia, resulting from the use of the so-called dental coil, which is used in taking dental films. I have seen other cases that showed a considerable atrophy of the skin accompanied by marked telangiectases, resulting from repeated exposures in the treatment of skin lesions. I agree with you that it is to be regretted that such a useful agent, both in therapeutic and diagnostic work, should get into ill repute in the minds of the medical profession as well as the laity. In my opinion it is all due to a lack of knowledge of the dangers of these so-called "harmless machines." There is absolutely no danger to the patient today, if certain precautions are observed. By interposing a leather or aluminum filter between the tube and the patient all danger is removed; also the tube should be at least fourteen inches from the skin-twenty is better. Under no circumstances should skin lesions be treated week after week, as is done in some cases, by this method."

Furthermore, while small superficial epitheliomata, such as have been treated successfully by dermatologists for many years by means of curetting and cauterization, may be equally well and painlessly removed by the $x$-rays, the large and deeper seated growths are distinctly unsuited to this method. Harm is frequently done by temporizing with these inadequate means when radical surgery is imperatively indicated. To emphasize once more the results of the abuse of this method of treatment, a patient not 
long ago was advised by me to undertake exposure to the $x$-ray for the healing of an epithelioma of the eyelid, that was not suited to radical excision. The practitioner who sent the patient to me for an opinion, objected that he had seen so many bad results from the use of the x-rays in therapeutics that he was inclined to abandon it altogether. This prejudice cannot be wondered at in view of the unfortunate results so frequently seen. It is a fair question for discussion whether, as at present employed, this method of treatment may not, on the whole, be a source of more harm than good.

It has not been my purpose in this article to discuss freely the dermatological uses of the $\mathrm{x}$-ray. This subject is far too extensive for my present space. Numerous lengthy articles, and even books dealing with this matter may be found in the literature. The x-ray has proved to be, in proper hands, a useful addition to our means of treating certain carefully selected cases of skin disease, especially the affections that I have mentioned. It is to the abuse of the method that I wish to call attention, and to show:-

1. That a great many cases of unnecessary disfigurement, more obvious than the original affection, are caused by an improper use of the x-rays.

2. That the cases suitable for this treatment can be selected only by those who have some considerable knowledge of skin affections.

3. That this method of treatment requires especial study and training and should not be regarded as an easy and safe procedure by those unskilled in its use.

\section{A STATISTICAL STUDY OF REMISSIONS IN GENERAL PARALYSIS.*}

by harlan l. paine, Danvers, mass.

(No. 36 of the Danvers State Hospital Contributions.)

Since the opening of the Danvers State Hospital there have been nearly 17,000 cases admitted, and of this number 1,420 were diagnosed as cases of general paralysis.

Southard, working with Danvers State Hospital material, reviewed 250 autopsied cases and concludes, regarding accuracy of diagnosis, in general paralysis, as follows: The accuracy of diagnosis in general paralysis was 9 out of 10 , that is to say, out of 10 cases, in which medical persons, or at least medical men of the average Danvers type, made the diagnosis, there would be one out of ten which would not turn out at autopsy to be a case of general paresis." Taking this percentage of error into consideration, there would be 1,279 that could reasonably be considered to be cases of general paralysis.

The clinical records of these 1,420 patients diagnosed as general paralysis have been analyzed and the cases that have shown remissions

* Read before the New England Society of Psychiatry, Oct. 3, 1912. studied. One hundred and thirty-two patients showed improvement to such an extent that it can be said that the patient had a remission. On analysis 37 of these cases were rejected as not showing enough symptoms to make the diagnosis certain, leaving 95 that were undoubted cases of general paralysis that showed a remission.

No case was considered a case of general paralysis that did not show the following physical signs: Alteration of the pupillary reaction, as sluggish or stiff reaction to direct light; alteration of knee jerks; motor incoördination as shown by impairment of speech, handwriting, or tremor.

For the mental picture it was required that the patient should show memory defect, judgment defect and some form of emotional disturbance.

The degree of improvement required to be considered a remission was that the patient should be up about, free from conduct disorder, able to care for himself in every way, showing no periods of confusion, delusions or hallucinations. Slight deterioration usually was noted in the histories of these cases.

The 95 cases that have been studied showed the above physical and mental symptoms during their stay in this hospital, and improved to the extent noted above.

Out of these cases considered, 47 were cases whose conduct and symptoms would place them in the class of the exhilarated form of general paralysis, 37 belonged to the demented type, 11 to the depressed type.

In 29 of the cases, $30 \%$, a history of syphilis was obtained, and the duration of the interval between the infection with syphilis, and the onset of the symptoms of general paralysis varied between 4 and 25 years, the average interval being 13 years and four months.

Eight of these cases received active antisyphilitic treatment; 6 at time of infection, 2 when their mental symptoms developed. In these 6 cases that received treatment at time of infection it is recorded that their treatment lasted two years. The average age of infection in 24 cases in which it could be ascertained was 24 years. The average age at which the general paralysis began in all the cases was 32 years.

Sixty-two of the cases gave a history of having been steady users of alcohol. In 7 it was definitely stated that the patient had never used alcohol.

In only 16 cases, or nearly $17 \%$ of the cases, were hallucinations recorded, 8 being wholly confined to the auditory sphere, 6 having both auditory and visual, 1 only visual, and 1 case suffering from all forms.

The duration of the general paralysis before the beginning of the remission varied between 2 months and 10 years, the average duration of the disease before remission being 1 year and 9 months.

The duration of the remission varied between 